\title{
IMIGRAÇÃO E EDUCAÇÃO NA PROVÍNCIA DO PARÁ: INSTRUÇÃO PRIMÁRIA NA COLÔNIA AGRICOLA DE BENEVIDES (1861-1881)
}

\author{
Vitor Sousa Cunha Nery ${ }^{1}$ \\ Maria do Perpétuo Socorro Gomes de Souza Avelino de França ${ }^{2}$
}

\begin{abstract}
Resumo
O objetivo deste artigo é analisar a implantação das escolas de instrução primárias na Colônia Agrícola de Benevides da província do Pará (1861-1881). Para atingir tal propósito metodologicamente nos apoiamos no tipo de pesquisa documental, que inclui relatórios dos diretores da instrução pública, relatórios dos presidentes da província do Pará, legislação educacional e os jornais da época como o "Diário do Gram Pará" e "O Liberal". Essas fontes foram pesquisadas na Biblioteca Pública do Pará Arthur Viana, Arquivo Público do Estado do Pará, Instituto Histórico e Geográfico Brasileiro e na Biblioteca Nacional. Para compreender as escolas primárias da colônia agrícola de Benevides na província do Pará na segunda metade do século XIX, nos apoiamos em teóricos da Nova História Cultural como Burke (2005), Chartier (2002), Julia (2001). As escolas primárias da colônia de Benevides funcionavam nos horários da manhã e da tarde para atender os filhos e filhas dos colonos estrangeiros e brasileiros com idades entre 6 e 15 anos, além de filhos de escravas alforriadas e crianças indígenas. No período da noite atendia os colonos adultos que desejavam aprender as primeiras letras.
\end{abstract}

Palavras-Chave: Imigração. Instrução primária. Província do Pará. Benevides. Século XIX.

\section{IMMIGRATION AND EDUCATION IN PARA PROVINCE IN: EDUCATION PRIMARY IN COLONY OF AGRICULTURAL BENEVIDES (1861-1881)}

\begin{abstract}
The aim of this paper is to analyze the implementation of the primary education schools in Cologne Benevides Agricultural of the province of Pará, in the second half of the XIX century. To achieve this purpose methodologically support in the type of desk research, which includes reports from directors of public education, reports of the presidents of the province of Para, educational legislation and the newspapers as the "Diary of the Grand Para" and "The Liberal". These sources were searched in the Public Library of Para Arthur Viana, Pará State Public Archives, Brazilian Historical and Geographical Institute and the National Library. To understand the primary schools of the agricultural colony of Benevides in Pará
\end{abstract}


province in the second half of the XIX century, we rely on theoretical New Cultural History as Burke (2005), Chartier (2002), and Julia (2001). Primary schools Benevides colony worked in the morning and afternoon hours to meet the sons and daughters of foreign settlers and Brazilians aged between 6 and 15 years, and children of alforriadas slaves and indigenous children. In the evening attended the adult settlers who wanted to learn the first letters.

Keywords: Immigration. Primary education. Province of Pará. Benevides. XIX century.

\section{INTRODUÇÃO}

A criação de colônias agrícolas na Amazônia foi uma forma encontrada pelos governos provinciais do Pará e do Amazonas para tentar resolver o problema da falta de alimentos durante o século XIX, causado pelo aumento da atividade extrativista da borracha na região. Nesse período, muitos agricultores abandonaram as suas plantações para viver do extrativismo da borracha que lhes garantia melhores lucros, devido o alto preço do produto nos mercados de Belém e Manaus.

As colônias agrícolas, também chamadas de núcleos coloniais, eram áreas de terras que deveriam ser ocupadas por colonos estrangeiros e nacionais. Para viverem nesses locais, os colonos eram submetidos a regras definidas pelo governo provincial e executadas pelos diretores das colônias. Esses diretores, nomeados pelos presidentes da província, eram responsáveis pelo núcleo colonial.

A implantação de colônias agrícolas na Amazônia teve início com a empresa do Barão de Mauá que instituiu, nessa região, a Companhia de Navegação e Comércio do Amazonas, em 1854. Uma das exigências feitas pelo governo brasileiro, para liberar a navegação do rio Amazonas para a companhia do Barão de Mauá, foi que a empresa fosse capaz de introduzir imigrantes estrangeiros nas províncias do Pará e Amazonas.

A Lei n. 226 de 15 de dezembro de $1853^{3}$ estimulou ainda mais o incentivo a imigração estrangeira para a região. Para isso, o governo deveria reservar dos seus recursos um determinado valor em dinheiro que seria emprestado a quem se propusesse a introduzir imigrantes europeus ou americanos na Amazônia. Esses imigrantes deveriam ser utilizados, prioritariamente, em estabelecimentos agrícolas, como as fazendas e os núcleos coloniais.

É fato que as colônias agrícolas criadas no Pará e Amazonas não serviram apenas para receberem imigrantes estrangeiros. Em 1877, uma grande seca atingiu as províncias do Nordeste do Brasil, obrigando muitos nordestinos a migrarem para Amazônia. Diante desse grande número de pessoas que chegou à região, os governos do Pará e Amazonas se viram obrigados a criar novas colônias agrícolas. 
Dentre as colônias agrícolas, existentes na Província do Pará, destacamos neste artigo, a colônia agrícola de Benevides, criada em 13 de junho de 1875 pelo presidente da província do Pará, Francisco de Sá e Benevides. A referida colônia foi batizada com o sobrenome desse presidente, tendo por finalidade colonizar a chamada Zona Bragantina. Em 1878, a colônia de Benevides passou a denominar-se Núcleo Colonial de Nossa Senhora do Carmo, em homenagem a Santa que o imperador D. Pedro II era devoto, não deixando de ser conhecido também como Benevides. A colônia foi instalada em terras situada às margens do antigo vazadouro dos Índios Tupinambás, conhecido também como estrada de Bragança. (MUNIZ, 1916).

O início do povoamento na colônia agrícola de Benevides com imigrantes estrangeiros data de 04 de junho de 1877, quando lá chegaram 180 imigrantes na sua maioria franceses, além de turcos, alemães, ingleses, italianos, espanhóis, belgas, americanos, suíços e portugueses. Os colonos estrangeiros que lá se instalaram fundaram vários engenhos e passaram a produzir e comercializar derivados da cana de açúcar. Além dos imigrantes estrangeiros, os brasileiros nordestinos, flagelados pela grande seca do final do século XIX, encontraram na colônia agrícola de Benevides um refúgio ideal para se instalarem na esperança de dias melhores. (PENTEADO, 1967).

Logo que os colonos chegaram à Benevides, foram recebidos pelo diretor da colônia, o empreiteiro Capitão Valentim José Ferreira, que vinha prestando serviços na estrada de ferro de Bragança desde o ano de 1866, no governo do então Presidente Pedro Leão Veloso. A maioria dessas famílias recebeu um pedaço de terra e passava a produzir para o próprio consumo. (NUNES, 2008).

Nas maiores propriedades, a produção de hortifrutigranjeiro era voltada para o mercado da capital da província do Pará, a cidade de Belém (com exceção dos derivados da cana de açúcar que eram comercializados para outras regiões do império). Benevides foi o primeiro núcleo colonial da antiga estrada de ferro de Bragança, contemplado com uma parada. Essa via férrea teve grande influência no desenvolvimento desse núcleo colonial, principalmente, porque a sua primeira parte construída ligava a localidade à capital da província do Pará, num total de $29 \mathrm{~km}$, inaugurada no dia 09 de novembro de 1884. (SANTOS, 1984).

A colônia de Benevides é também conhecida como "Terra da Liberdade", pois quatro anos antes da Princesa Izabel abolir a escravatura no Brasil, esta foi abolida na província do Pará, em Benevides precisamente. A festa da libertação ocorreu no dia 30 de março de 1884 quando General Rufino Galvão (Visconde Maracajú), partiu de Belém com destino a Benevides para presidir a Sessão Magna da libertação dos escravos dessa Colônia.

Assim, considerando esse cenário, nos propomos, neste artigo, analisar a implantação das escolas de instrução primárias da Colônia Agrícola de Benevides da província do Pará (1861-1881). Para atingir tal propósito, metodologicamente, nos apoiamos no tipo de pesquisa documental. As fontes documentais compreendem os relatórios de presidentes da 
província do Pará, os relatórios de diretores da instrução pública, a legislação educacional e os jornais: "Diário do Gram Pará" e "O Liberal". Essas fontes foram pesquisadas na Biblioteca Pública do Pará Arthur Viana, no Arquivo Público do Estado do Pará, no Instituto Histórico e Geográfico Brasileiro e na Biblioteca Nacional.

Os documentos "oficiais", como os relatórios de presidentes da província do Pará e dos diretores da instrução pública, se mostraram relevantes fontes para esta pesquisa, pois, por meio deles, foi possível fazer o mapeamento geográfico e estatístico da instrução pública na província do Pará, nos anos de 1861 a 1881. Para Gatti Júnior e Araújo (2002), esses documentos, além de permitirem perceber a "fala" oficial e autorizada, servem igualmente para comparar e relacionar, no corpo dos relatórios, a instrução pública com as demais esferas do poder público provincial, por exemplo, a saúde, o comércio, a infraestrutura, dentre outras.

As legislações educacionais e os regulamentos escolares também foram utilizados na pesquisa. Segundo Faria Filho (2002), esses documentos, reconhecidos como práticas sociais e produzidos pelos sujeitos históricos, remeterem a diversos aspectos da vida social e revelam seus interesses e desejos, configurando-se, enquanto espaços, objeto e objetivo de lutas políticas.

Os jornais locais permitiram descortinar um novo mundo, ricos em detalhes e dinâmicos, no âmbito das relações sociais. De acordo com Nóvoa (1997), os jornais não apenas servem para fornecer a memória dos percursos educacionais, mas, sobretudo, permitem compreender que não há nenhum determinismo na evolução dos sistemas educativos, das ideias pedagógicas ou das práticas escolares, uma vez que tudo é produto de uma construção social.

Para compreender a implantação das escolas primárias da colônia agrícola de Benevides na província do Pará (1861-1881), nos apoiamos em teóricos da Nova História Cultural como Burke (2005), Chartier (2002) e Julia (2001).

Sobre a História Cultural, Burke (2005) menciona a emergência dos aspectos culturais no que diz respeito aos estudos relacionados ao comportamento humano como centro privilegiado do conhecimento histórico. Assim, esquemas teóricos generalizantes foram abandonados, havendo uma valorização de grupos particulares, como exemplo, professores e alunos das escolas primárias da colônia agrícola de Benevides da província do Pará, na segunda metade do século XIX.

A História Cultural, segundo Chartier (2002, p. 16), tem por “[...] principal objeto identificar o modo como em diferentes lugares e momentos uma determinada realidade social é construída, pensada e dada a ler”. O autor esclarece também que:

As percepções do social não são de forma alguma discursos neutros: produzem estratégias e práticas (sociais, escolares, políticas) que tendem impor uma autoridade à custa de outros, pois elas menosprezadas a legitimar um projeto 
reformador ou a justificar, para os próprios indivíduos, as suas escolhas e condutas [...]. As lutas de representação tem tanta importância como as lutas econômicas para compreender os mecanismos pelos quais um grupo impõe, ou tenta impor, a concepção do mundo social, os valores que são os seus, e o seu domínio. (2002, p. 17).

A História Cultural é o resultado de um diálogo que se estabeleceu, desde os anos de 1960, entre a sociologia, a antropologia e a história. Nessa abordagem, a cultura é entendida como:

Uma forma de expressão e tradução da realidade que se faz de forma simbólica, ou seja, admite-se que os sentidos conferidos às palavras, às coisas, às ações e aos atores sociais se apresentam de forma cifrada, portanto, já é um significado e uma apreciação valorativa. (PESAVENTO, 2008, p. 15).

Para Chartier (2002, p. 11), cultura "[...] é um conjunto de significações historicamente transmitidas e inscritas em símbolos por meio das quais os homens comunicam, perpetuam e desenvolvem seu saber sobre a vida, suas atitudes diante dela". Diante disso, no âmbito da história da educação, segundo Souza (2000), nos últimos anos, o termo "cultura escolar" adquiriu uma significativa potencialidade explicativa e passou a se constituir em objeto de pesquisa e, de certa maneira, em uma abordagem aglutinadora, e que tem sido amplamente empregado, associado à reconceitualização do trabalho histórico em educação.

Julia (2001, p. 6) define cultura escolar como um "[...] conjunto de normas que definem conhecimentos a ensinar e condutas a inculcar, e um conjunto de práticas que permitem a transmissão desses conhecimentos e a incorporação desses comportamentos".

Essa nova forma de escrever a história da educação, "[...] tem possibilitado olhar a educação escolar no Império de um ponto de vista enriquecido [...]”. (HILSDORF, 2003, p. 41). As pesquisas sobre a instrução primária, no período imperial, têm trazido à luz vários aspectos que estavam na penumbra, na invisibilidade, permitindo traçar um novo "quadro geral" da instrução pública primária no Brasil, no século XIX e, no caso deste estudo, também na Amazônia.

\section{DISSEMINAÇÃO DA INSTRUÇÃO PÚBLICA NA PROVÍNCIA DO PARÁ}

Na segunda metade do século XIX, os governantes da província do Pará, empregaram em seus discursos os termos disseminar, difundir, propagar e estender a instrução pública a todos: as "classes populares", as "massas" e as "mais longínquas localidades". 


\section{Revista HIISTIFIDIBR On-line}

ISSN: 1676-2584

Artigo

doi: $10.20396 /$ rho.v17i2.8645851

Com base no conceito de Chartier (2002), é possível observar que as representações do mundo social são expressas nos discursos políticos contidos na documentação oficial: legislações, relatórios e ofícios de dirigentes locais.

Esses discursos estiveram presentes na legislação e nas práticas educacionais dos presidentes da província do Pará. Notícia, veiculada no jornal Província do Pará do ano de 1876, expressou a aspiração das autoridades da província no referido período, imbuídos do desejo de estender a instrução popular aos mais longínquos lugares.

[...] Queremos a instrucção (sic) primaria (sic) derramada por todos os ângulos, por todas as cidades, por todas as villas (sic), aldêas (sic), freguesias (sic), povoações da província. Onde houver um fôlego humano para quem o alphabeto (sic) for um phantasma (sic), um enigma indecifrável, ahi (sic) queremos um professor. Porque só assim attingiremos (sic) o pé de nação civilizada (sic), porque emfim (sic) só a luz da instrucção (sic) pode libertar o povo brasileiro da ignorância em que se debate [...]. (PARÁ, 1876, p. 3).

Essa representação da instrução, como uma fórmula de transformação do homem, vem ao encontro do pensamento que circulava pelo território brasileiro, que percebia a escolarização da população, sobretudo a das camadas mais pobres, como um imperativo para o desenvolvimento do Estado nacional e da civilidade.

Esse anseio trazia consigo o desafio das enormes distâncias que separavam as povoações da província do Pará, tanto que o acesso a muitas localidades só era possível por meio dos rios.

Segundo Rizzini (2004), a população da província do Pará vivia dispersa pelo vasto território, dedicava-se às atividades extrativas e a pequena agricultura, em sítios afastados dos núcleos populacionais, o que constituía enorme desafio à difusão da instrução primária. Tal argumento foi explorado exaustivamente pelos presidentes da província do Pará, em seus relatórios.

Nas décadas de 1860 e 1870, houve, por parte do governo provincial paraense, intensa mobilização em 'prol' da instrução pública primária, quando os relatórios provinciais registraram significativo aumento no número de escolas e de alunos matriculados, conforme podemos observar no Quadro 1 a seguir:

\begin{tabular}{|c|c|c|c|c|c|c|}
\hline Ano & \multirow{2}{*}{$\begin{array}{c}\mathbf{N}^{\mathbf{0}} \mathbf{d e} \\
\text { Escolas }\end{array}$} & Masculinas & Femininas & \multicolumn{3}{|c|}{ Matriculas } \\
\cline { 5 - 7 } & & & Meninos & Meninas & Total \\
\hline $\mathbf{1 8 4 0}$ & 37 & 36 & 01 & 738 & 25 & 763 \\
\hline $\mathbf{1 8 4 8}$ & 43 & 41 & 02 & 875 & 39 & 914 \\
\hline $\mathbf{1 8 4 9}$ & 41 & 38 & 03 & 977 & 110 & 1.087 \\
\hline $\mathbf{1 8 5 0}$ & 42 & 38 & 04 & 1.158 & 134 & 1.292 \\
\hline $\mathbf{1 8 5 2}$ & 45 & 40 & 05 & 1.191 & 163 & 1.354 \\
\hline $\mathbf{1 8 5 3}$ & 49 & - & - & 1.266 & 180 & 1.446 \\
\hline
\end{tabular}

Rev. HISTEDBR On-line, Campinas, v.17, n.2 [72], p.490-510, abr./jun. 2017 


\section{Revista HIISTHWIDIR On-lime}

ISSN: 1676-2584

\begin{tabular}{|l|c|c|c|c|c|c|}
\hline $\mathbf{1 8 5 4}$ & 52 & 45 & 07 & 1.610 & 250 & 1.860 \\
\hline $\mathbf{1 8 5 6}$ & 75 & - & - & - & - & - \\
\hline $\mathbf{1 8 5 7}$ & 76 & 62 & 14 & - & - & - \\
\hline $\mathbf{1 8 5 9}$ & 80 & 64 & 16 & 3.102 & 577 & 3.679 \\
\hline $\mathbf{1 8 6 1}$ & 77 & - & - & - & - & 3.736 \\
\hline $\mathbf{1 8 6 2}$ & - & - & - & - & - & 3.552 \\
\hline $\mathbf{1 8 6 3}$ & 88 & - & - & 2.709 & 660 & 3.369 \\
\hline $\mathbf{1 8 6 4}$ & 99 & 66 & 26 & 2.908 & 674 & 3.582 \\
\hline $\mathbf{1 8 6 6}$ & 119 & 95 & 24 & 2.563 & 567 & 3.140 \\
\hline $\mathbf{1 8 6 7}$ & 97 & 73 & 24 & - & - & 4.176 \\
\hline $\mathbf{1 8 7 0}$ & 107 & 80 & 27 & 3.778 & 882 & 4.660 \\
\hline $\mathbf{1 8 7 2}$ & 164 & 92 & 72 & - & 1.012 & - \\
\hline $\mathbf{1 8 7 5}$ & 226 & - & - & 4.580 & - & - \\
\hline $\mathbf{1 8 8 0}$ & 250 & 174 & 71 & - & - & - \\
\hline
\end{tabular}

Quadro 1 - Número de escolas primárias públicas e alunos matriculados na província do Pará (1840-1880). Fonte: Pará, Relatórios de presidentes da província do Pará (1840-1880).

Os dados escolares, divulgados pela diretoria de instrução pública da província do Pará, basearam-se em mapas enviados pelos professores públicos. Mas, esses mapas eram considerados, quase unanimemente, como irreais, visto que, muitas vezes, os professores anotavam o número de alunos matriculados, mas não os que efetivamente frequentavam as aulas.

Apesar de não citarmos aqui todas as estatísticas sobre a instrução primária paraense, consideramos relevante mencionar a importância que os números da educação escolar assumem para o governo provincial naquele período. Eles exibem, de um lado, a valorização dada por determinada administração à educação de seus governados e, por outro, expõem as dificuldades enfrentadas para investir em uma das áreas em que os discursos eram mais exaltados: da educação e da instrução popular.

As condições materiais e humanas de funcionamento das escolas são indicadores do investimento limitado do Estado nesse período. Alguns relatórios dos presidentes da província do Pará denunciaram que as condições de funcionamento das casas escolares não eram as mais apropriadas. A maioria das escolas primárias na província do Pará funcionava em casas alugadas ou nas casas dos próprios professores. As escolas deveriam ser providas de papel, penas, tintas, lápis e compêndios para serem distribuídos para os alunos pobres. Outros objetos como bancos e carteiras para escrita, deveriam ser fornecido pelos professores, conforme estabelecido no regulamento da escola primária, publicado no jornal Diário do Gram-Pará em 3 de maio de 1860. Em seguida, analisaremos uma das estratégias de disseminação da instrução pública primária na província do Pará, na segunda metade do século XIX, que foi a criação de escolas primárias em colônias agrícolas, no caso deste estudo, na colônia de Benevides. 


\section{CRIAÇÃO DE ESCOLAS PRIMÁRIAS AGRÍCOLAS}

A colônia agrícola de Benevides foi criada em 13 de junho d 1875, mas já na década de 1860, o governo provincial paraense já vinha pensando em instalar um projeto educacional de formação técnica agrícola, nessa região, mais especificamente na Fazenda Pinheiro, com o propósito de abrigar os imigrantes estrangeiros e as populações que estavam dispersas no interior da província.

Julia (2001, p. 19) afirma que "[...] mais que nos tempos de calmaria, é nos tempos de crise e de conflitos que podemos captar melhor o funcionamento real das finalidades atribuídas à escola". De acordo com o diretor da instrução pública da Província do Pará, Felix Barreto de Vasconcellos, as escolas implantadas mal acomodavam os alunos durante o dia. No interior, as escolas funcionavam nas Igrejas, palhoças ou casas acanhadas, pois, em muitos lugares, só existia a casa do pároco. (INSTITUTO HISTÓRICO..., 1858).

Uma das primeiras escolas, criadas na região da futura colônia agrícola de Benevides, foi a "Escola Rural D. Pedro II", em 1861, que tinha como objetivo desenvolver a lavoura de cana de açúcar e a pecuária, conforme o seu regimento. A escola funcionava na "Fazenda provincial Pinheiro", situada na confluência do rio Maguary com o Guajará, em um lugar aprazível e saudável, nas proximidades de Belém. (PARÁ, 1861, p. 13).

De acordo com Nunes (2011, p. 372), a educação agrícola - materializada na implantação da "Escola Rural D. Pedro II", que objetivava assegurar valores associados à ideia de prosperidade, progresso e civilização - fazia parte dos interesses dos grupos sociais da Amazônia. Mas, por outro lado, o entendimento de que cabia ao Estado se responsabilizar por tudo que dissesse respeito às escolas públicas, seus representantes não se furtaram em assinalar a inércia dos governos em prover as escolas de mobília adequada e materiais, como: papel, tinta e compêndios.

$\mathrm{Na}$ “Escola Rural D. Pedro II" era ministrado o Ensino Primário, além das práticas agrícolas, ensinando tanto na teoria quanto na prática. Ela se destinava a formar trabalhadores, operários, feitores e administradores para trabalharem nos estabelecimentos rurais na província do Pará. Tinham acesso a esse ensino, de preferência órfãos desvalidos, filhos de ex-escravos, índios e colonos estrangeiros de poucas posses, tanto no sistema de internato quanto externato, enfim, acolhiam todas as pessoas que quisessem se instruir nessa modalidade educativa. (PARÁ, 1861 p. 13).

A “Escola D. Pedro II" se caracterizava como instituição primária de agricultura, mais prática do que teórica, mais especulativa do que experimental. A ela competia inserir os educandos primeiramente na prática agrícola, ensinando-os a ler, a gravar na memória os princípios da agricultura, mostrando no campo dos trabalhos a aplicação desses princípios. (NUNES, 2014, p. 176). 
Para Jacomeli e Molina (2010, p. 11), no geral, essas instituições formadoras, como a escola D. Pedro II, tinham uma concepção pedagógica baseada no método intuitivo, sob a inspiração estadunidense e francesa e projetavam um ensino profissionalizante, onde as atividades teóricas eram minoritárias e os exercícios práticos majoritários.

A escola rural se afirmaria como espaço de combate àquilo que se convencionou chamar de "vida ambulante" dos povos amazônicos, numa referência aos constantes deslocamentos das populações pelo interior da floresta. (NUNES, 2011, p. 372).

Acreditava-se que as crianças com os novos aprendizados no espaço escolar rural, principalmente de valorização da agricultura em detrimento a outras atividades econômicas, seriam importante elemento para convencer os pais a desenvolverem atividades agrícolas, assim permitiriam que as experiências desenvolvidas na escola rural pudessem ser transportadas para as lavouras particulares, dinamizando a produção e aumentando os recursos dos proprietários.

Segundo Nery (2013, p. 63), os objetos pertencentes às escolas da província, inclusive da escola agrícola D. Pedro II, tais como: mesas de várias dimensões, carteiras ou escrivaninhas, relógios, vasilhas de água, copos, cadeiras de braço e bancos de assento de várias dimensões compunham, ou deveriam compor, o conjunto de elementos permanentes de cada unidade escolar, eram considerados mobiliários escolares por serem fixos ao espaço físico do estabelecimento de ensino.

No que se refere à escola primária agrícola D. Pedro II, outra materialidade foi levada em consideração para implantação da escola:

[...] nove milhas de distância, por água, e outras tantas por terra, da cidade de Belém, consistia em mais um condicionante favorável para a implantação da escola D. Pedro II, na fazenda Pinheiro, isto porque não estava afastava do núcleo urbano da província, a ponto que facilitaria mandar diretamente ao mercado seus produtos. (PARÁ, 1861, p. 13).

Por outro lado, se pretendia que a fazenda Pinheiro, se constituísse em espaço para recebimento de colonos, principalmente estrangeiros, pois a expectativa era que, em breve tempo, as terras da fazenda e do seu arredor iriam se valorizar com a criação da colônia agrícola de Benevides em 1875. A instalação da escola D. Pedro II, na fazenda Pinheiro permitiria essa valorização, atraindo colonos que buscavam se utilizar dos conhecimentos desenvolvidos com ensino agrícola.

Esperava-se que muitos desses colonos, incluindo, imigrantes estrangeiros, prefeririam se estabelecer em terras nos arredores da fazenda, por isso, o governo provincial solicitou autorização da Assembleia Legislativa da província para que essas terras fossem "[...] divididas e aforadas a quem nelas quisessem se estabelecer, dedicando-se a lavoura da cana para moerem na fábrica do próprio estabelecimento de ensino”. (PARÁ, 1861, p. 13). 
Ao se considerar o regulamento de criação da Escola Agrícola "D. Pedro II", de 01 de maio de 1861, constatamos que a escola compreenderia uma instituição de instrução primária, onde o educando desenvolveria o ofício de leitura, tendo como temática os rudimentos da agricultura e os princípios que pontuavam a atividade agrícola como a mais importante das tarefas, sendo que, nesse espaço de aula, se aproveitaria para apresentar as conferências teóricas e o ensino religioso e moral.

A implantação da escola D. Pedro II, na província do Pará, surgiu em um momento de entusiasmo do Ministério da Agricultura com a defesa do ensino agrônomo no país, conforme registra o relatório do Ministério da Agricultura de 1861, onde foram implantadas quatro associações rurais nas respectivas províncias: Bahia, Sergipe, Pernambuco e Rio de Janeiro. O compromisso dessas entidades era a "[...] criação de escolas normais de agricultura”. (BRASIL, 1862, p. 11).

Segundo Del Priore e Venâncio (2006), esses estabelecimentos de ensino tinham por objetivo, conforme defendia o próprio Ministério da Agricultura, "regenerar" a mão de obra do campo, tanto no que dizia a respeito aos efeitos negativos da escravidão, quanto ao desejo de que novas técnicas de plantio fossem desenvolvidas, a ponto de expandir as áreas agrícolas não apenas do ponto de vista territorial, mas de implementos e máquinas.

A expectativa era que à medida que houvesse o crescimento dos lucros da Escola Rural D. Pedro II, aumentasse também o número de internos de modo a poder ser ali recebido todos os jovens, incluindo indígenas, encaminhados pelas autoridades competentes e em poucos anos se espalharia pelo interior da província do Pará.

De acordo com Rizzini (2004 p. 23), a educação na região amazônica no século XIX, especialmente na província do Pará, era acompanhada de uma perspectiva de sedentarizar a população do interior. Tratava-se, segundo a autora, de necessidades reclamadas pelos administradores locais, o que estava associado em geral às comunidades indígenas.

Após a criação da colônia agrícola de Benevides em 1875, houve um número significativo de imigrantes estrangeiro de diversas nacionalidades, como: franceses, italianos espanhóis, belgas, suíços, portugueses e, ainda, brasileiros, particularmente nordestinos foram atraídos para aquele lugar. Não se sabe o certo o número de indivíduos que teriam entrado na colônia de Benevides.

De acordo com Muniz (1916), haviam entrado, na colônia de Benevides, 364 pessoas, mas apenas 117 teriam permanecido no núcleo. Bulamarqui (1984) afirma que 179 teriam se deslocado para a referida colônia, tendo restado somente 32. Mais tarde, a colônia de Benevides assumiu um caráter misto, recebendo um número considerável de nordestinos, particularmente de cearenses. 


\section{ESCOLAS PRIMÁRIAS NA COLÔNIA AGRÍCOLA DE BENEVIDES}

Segundo o relatório do presidente da província, José Coelho de Gama e Abreu, após a criação da colônia agrícola de Benevides, foram implantadas algumas escolas de instrução primárias. A diretoria deste estabelecimento, nos primeiros meses de 1879 , esclarecia em ofício, enviado a diretoria de instrução pública, em 2 de agosto de 1880, que lá funcionava uma escola para crianças do sexo feminino, duas do sexo masculino e uma noturna, que atendiam alguns colonos que tivessem interesse em aprender as primeiras letras. (PARÁ, 1881, p. 1).

A princípio, a implantação de uma instituição pública de instrução primária, em Benevides, tinha como objetivo atender a imigração europeia. Porém, os primeiros imigrantes estrangeiros que chegaram na região onde seria fundada a futura colônia de Benevides, segundo o relatório do presidente da província, Domingos José da Cunha Júnior, revelou considerável contraste em relação às imagens difundidas no Brasil, que associavam imigrante, principalmente europeu, como capaz de "preparar e cultivar as terras", elevando as profissões agrícolas na província do Pará, visto que os que chegaram à Colônia Benevides não se mostraram preparados para tanto. (PARÁ, 1853, p. 25).

Com a chegada de várias famílias de migrantes nordestinos e a existência de muitas crianças, foi criada a primeira escola primária da colônia agrícola de Benevides, segundo o jornal $O$ Liberal do Pará de 6 de abril de 1879, a seção feminina dessa escola estava sob à direção da professora Filomena Rodrigues da Silva, que cuidava da educação das meninas; a educação do sexo masculino sob os cuidados do padre Lyra e do professor José Valhão de Vasconcelos. A noite havia aula para jovens e adultos que esteve sob a guarda do professor Antonio Duarte Balby. (O LIBERAL..., 1879, p. 01).

A falta de professores habilitados para o magistério era outra questão bastante discutida nesse período, o diretor de instrução pública Felix Barreto de Vasconcelos, constatou que havia "[...] crescido o numero de escolas de ensino primário disseminadas por toda província", mas poucos professores mereciam este "[...] honroso titulo". (INSTITUTO HISTÓRICO..., 1858, p. 4).

Segundo Rizzini (2004), a dificuldade em arregimentar pessoas preparadas para lecionarem em "lugarejos que são menos que aldeias" levaram as administrações a prover os lugares de professores primários com sacerdotes interinos, ou mesmo aprovando em concurso professores não habilitados e tinha também a simples indicação de professores pelos governos.

O ensino da leitura e escrita, associado aos valores religiosos constituía a base de ensinamento nessas escolas; situação que pode ser evidenciada pela apresentação do nível de conhecimento dos alunos avaliada pelo padre Lyra, além da presença do pároco como um dos professores. De acordo com os dados da administração da colônia, dos 161 alunos matriculados de $1^{\circ}$ de agosto a 6 de setembro de 1878, e que estavam sob os cuidados do 
padre Lyra, esse fazia questão de destacar que: “[...] 143 começavam a ler o "a-b-c", sendo que13 balbuciavam as primeiras sílabas, 3 já soletravam nomes, e outros 3 possuíam princípios de leitura”. (O LIBERAL..., 1879, p. 01).

Segundo Nery (2013, p. 47), a formação ofertada aos professores da província do Pará, baseava-se quase que totalmente, para não dizer de forma integral, em orientações morais, difundidas pela Igreja e pelo Estado, que eram explicitadas no corpo normativo da instrução pública que regia o funcionamento das escolas de primarias.

Esses direcionamentos morais articulavam-se com os conteúdos de ensino de cada disciplina escolar. No que diz respeito ao ensino da leitura e da escrita, havia um incentivo para que fosse empreendido, prioritariamente, por textos legislativos e/ou de cunho religioso, pois, ao mesmo tempo em que os alunos fossem instruídos nas letras, eles também seriam educados, de modo a conhecer seus direitos e cumprir os deveres, sem contrariar os preceitos do Estado.

O programa de ensino das escolas de instrução pública primárias da colônia de Benevides compreendia os ensinamentos de leitura, escrita, quatro operações aritméticas, noções práticas do sistema métrico, doutrina cristã e da religião do Estado, e costura para as meninas. No caso de ensinamentos mais adiantados, como: a gramática portuguesa, a caligrafia, o desenho linear, a aritmética avançada, os elementos de geometria, de geografia e de história. (O LIBERAL..., 1879).

Ao estudar a cultura escolar, Julia (2001, p. 33) considera interessante realizar um inventário sistemático das práticas escolares, com a intenção de "[...] compreender as modificações, frequentemente insensíveis, que surgem de geração em geração”.

Convém examinar atentamente a evolução das disciplinas escolares, levando em conta diversos elementos que, em ordem de importância variada, compõem esta estranha alquimia: os conteúdos ensinados, os exercícios, as práticas de motivação e de estimulação dos alunos, que fazem parte destas 'inovações' que não são vistas, as provas de natureza quantitativa que asseguram o controle das aquisições. (JULIA, 2001, p. 34).

O autor acrescenta que as disciplinas escolares “[...] não são nem uma vulgarização nem uma adaptação das ciências de referência, mas um produto específico da escola, que põe em evidência o caráter eminentemente criativo do sistema escolar". (JULIA, 2001, p. 34).

Nessa mesma perspectiva, Chervel (1990, p. 180) rebate a ideia de que os conteúdos de ensino impostos à escola pela sociedade são transportados para o espaço escolar tal como foram produzidos socialmente. Logo, essa produção específica da escola não se desvincula das finalidades educativas advindas da sociedade.

A criação de escolas primárias na Colônia Benevides estava circunscrita a um contexto, marcado por discursos que tinham como propostas a disseminação da instrução Rev. HISTEDBR On-line, Campinas, v.17, n.2 [72], p.490-510, abr./jun. 2017 
pública a todos os habitantes da província. De acordo com as autoridades provinciais, o desafio era a expansão das escolas aos lugares distantes e pouco povoados.

O conceito de ensino, pensado pelas autoridades locais, remetia ao surgimento de um espaço educacional articulado aos interesses do Estado. No entanto, há de se considerar as resistências, conflitos e diversidades de práticas pedagógicas que caracterizaram a implantação e implementação da forma moderna de educação pensada para o país.

As escolas públicas primárias, responsáveis pelo ensino das primeiras letras, eram quase sempre isoladas; ou seja, cada escola tinha um professor que regia uma aula, atendendo a alunos de várias idades, entre 6 e 15 anos.

No caso de escolas com grande número de alunos, estas podiam ter o auxílio de um professor adjunto, o que não resolvia o problema do ensino simultâneo, visto que crianças de diferentes faixas etárias e adiantamentos frequentavam o mesmo espaço, conforme ofício da diretoria de instrução pública, publicado no jornal $O$ Liberal do Pará em 1879, endereçado ao Delegado Literário do Núcleo Colonial de Benevides.

Ao delegado literário do Núcleo Colonial de Nossa Senhora do Carmo de Benevides, informe qual a frequência da escola regida pelo professor interino José Valião de Oliveira, e se o mesmo carece de um adjunto, enviando-me um mapa dos alunos matriculados na referida escola. (O LIBERAL..., 1879, p. 1).

A casa utilizada como escola era alugada pelo professor ou professora que, nesse mesmo espaço, morava com a família, reservando um dos cômodos para a função pública; o que não deixava de se constituir em edifícios improvisados. A escolha da casa cabia ao mestre; o que levava os visitadores das escolas, responsáveis pela fiscalização desses estabelecimentos, a denúncia de que, em geral, as residências eram acanhadas, antihigiênicas e sem ventilação.

No interior, faltavam habitações apropriadas, levando, em alguns casos, à instalação de escolas em verdadeiras palhoças. A falta de utensílios, mobílias e livros faziam com que os professores a utilizassem o que tinham à mão e ao que estavam habituados. Os meios disciplinares, quase sempre, extrapolavam o permitido por lei, fazendo com que as crianças aprendessem sob o jugo do "terror do mestre", como diziam alguns visitadores. No caso específico da colônia Benevides, as escolas funcionavam em prédios improvisados, sendo uma nas proximidades da Igreja de Nossa Senhora do Carmo e outra nos fundos da diretoria do núcleo. Essas duas escolas atendiam até 50 crianças, cada uma. (O LIBERAL..., 1879).

As dificuldades de se implantar um ensino regular, na província do Pará, que garantisse a permanência dos educandos nas escolas públicas resultavam de duas situações: de um lado, não havia ações do poder público para criar espaços condizentes e capazes de atender os educandos; por outro, havia uma resistência dos colonos em encaminhar os filhos para os improvisados estabelecimentos de ensino. 
Nesse caso, o diretor de instrução pública do Pará em 1877, Joaquim Pedro Corrêa de Freitas, lamentava que boa parte das escolas fossem pouco frequentadas, devido ao período de colheita da borracha, quando os povoados eram abandonados por muitos de seus habitantes. (PARÁ, 1877).

Os estudos sobre a instrução nas diversas localidades do Pará, incluindo as escolas implantadas nos núcleos coloniais, reforçam a ideia de que a atividade extrativa seria o grande obstáculo para o desenvolvimento do ensino.

Sobre essa questão, Joaquim Pedro Corrêa de Freitas identificou que nos locais "[...] em que eram mais disseminadas a população, menos frequentadas eram as escolas"; outra observação é quanto aos lugares em que a população "[...] entrega-se à extração da borracha"; as escolas, em certa época do ano, "[...] ficam quase despovoadas", ao passo que as escolas implantadas em localidades que vivem da lavoura e da pesca, "[...] estas têm grande número de alunos matriculados, e a frequência nos diversos meses do ano é quase sempre a mesma". (PARÁ, 1877, p. 41).

Nesse aspecto, de acordo com o relatório do presidente, Francisco Maria Corrêa de Sá e Benevides, a lavoura deveria ser responsável pela mudança de hábitos dos colonos na província do Pará, uma vez que, por meio da agricultura, eles deixariam a "vida errante" em que estavam habituados. (PARÁ, 1876, p. 6).

A agricultura seria um importante elemento de garantia de fixação do colono em determinada área, ao contrário do extrativismo, não exigindo constantes deslocamentos das populações pelo interior da província. Mas, na colônia Benevides, a agricultura teve outro efeito, quando relacionada à criação de espaços de instrução pública primária, como exemplo, a pouca presença de crianças frequentando o núcleo colonial.

A necessidade de se garantir as atividades de cultivo exigia o uso quase constante do trabalho das crianças, o que inviabilizava a sua frequência na escola. E a agricultura embora fixasse o homem a terra, a esta era ainda atribuída à capacidade de facilitar a propagação do modelo de educação pensada pelas autoridades imperiais.

No entanto, há de se considerar que a identificação dos colonos com o modelo proposto de educação e a dinâmica de trabalho pareceu se constituir como elementos decisivos, seja para facilitar a implantação e implementação dessas escolas, seja para negálas.

\section{CONSIDERAÇÕES FINAIS}

As experiências das colônias agrícolas amazônicas no século XIX contribuíram para expansão da instrução pública no interior da província do Pará e revelaram práticas e culturas 
escolares que nos ajudam a compreender a implantação das escolas primárias na colônia de Benevides.

As escolas primárias da colônia de Benevides funcionavam nos horários da manhã e da tarde para atender os filhos e filhas dos colonos estrangeiros e brasileiros com idades entre 6 e 15 anos, além de filhos de escravas alforriadas e crianças indígenas. No período da noite atendia os colonos adultos que desejavam aprender as primeiras letras.

A primeira escola primária a ser implantada na região de Benevides, foi a Escola Agrícola D. Pedro II, em 1861, que tinha como objetivo profissionalizar e racionalizar a atuação das classes dominantes no campo (qualificando o proprietário ou possíveis funcionários de fazenda ou outros estabelecimentos rurais), desde a infância, preparando-os para os trabalhos agrícolas, pois se entendia que a agricultura se constituía no caminho para o combate dos costumes considerados não civilizados e a implantação de novos hábitos, condizentes com o que se defendia como sociedade moderna.

Na escola primária agrícola D. Pedro II, os educandos desenvolviam o ofício de leitura, tendo como temáticas os rudimentos de agricultura e os princípios que pontuavam a atividade agrícola como a mais importante das tarefas. Essa prática de leitura era dirigida pelo capelão que, além de ter a função de celebrar os ofícios divinos dentro do estabelecimento, acumulava a função de professor.

Após a criação da colônia agrícola de Benevides em 1875, com a chegada de várias famílias de imigrantes estrangeiros e migrantes nordestinos, em 1877, houve um crescimento no número de crianças e, com isso, a necessidade de se instalar escolas de instrução pública primária, sendo que no ano de 1880, já havia sido implantada quatro classes de instrução primária, uma para crianças do sexo feminino, duas para as crianças do sexo masculino e uma noturna para atender os jovens e adultos. Os professores dessas escolas eram a professora Filomena Rodrigues da Silva, que ensinava a classe de meninas; o professor padre Lyra e do professor José Valhão de Vasconcelos que ensinavam a classe dos meninos; e o professor Antonio Duarte Balby que lecionava na escola noturna.

O ensino da leitura e escrita, associado aos valores religiosos, constituía a base de ensinamento das escolas de instrução pública primária da colônia de Benevides e o seu programa de ensino compreendia as seguintes disciplinas: leitura, escrita, quatro operações aritméticas, noções práticas do sistema métrico, doutrina cristã e da religião do Estado, e costura para as meninas.

O método de ensino utilizado era o simultâneo que exigia um conjunto de elementos materiais (papel, tintas, penas, tinteiros, bancos coletivos, compêndios etc) que dessem sustentação às práticas desenvolvidas por professores e alunos. O método de ensino que deveria ser utilizado pelos professores não chegou a ser efetivado, tendo por base o seu modelo original, devido à falta de edifícios apropriados e de material adequado. 
As escolas de instrução pública primárias da colônia de Benevides funcionavam em prédios improvisados, como: igrejas, nos fundos de sedes comunitárias e na própria casa do professor. A ausência de um espaço adequado acabava por impedir que a escola se tornasse mais efetiva, simbólica e materialmente, junto à população.

Embora a lavoura fosse vista como um importante elemento de garantia de fixação do colono em determinada área, ao contrário do extrativismo, pois não permitia constantes deslocamentos das populações pelo interior da província. Na Colônia Benevides, a agricultura teve outro efeito quando relacionada à criação de espaços de instrução pública primária, como exemplo, a pouca presença de crianças frequentando o núcleo colonial. A necessidade de se garantir as atividades de cultivo exigia o uso quase constante do trabalho das crianças, o que inviabilizava a sua frequência na escola.

\section{REFERÊNCIAS}

BRASIL. RELATÓRIO do ano de 1861 apresentado a Assembléia Geral na 2 Sessão da $11^{\circ}$ Legislatura pelo Ministro e Secretário dos Negócios da Agricultura, Comércio e Obras Públicas Manuel Felizardo de Souza de Melo. Rio de Janeiro: Typographia Universal de Lamert, 1862.

BULAMARQUI, R. Transformações demográficas numa economia extrativa: Pará 1872-1920. 1984. 145 f. Dissertação (Mestrado) - Universidade Federal do Paraná, Curitiba, 1984.

BURKE, P. O que é história cultural? Rio de Janeiro: Jorge Zahar, 2005.

CHARTIER, R. O mundo como representação. In: . À beira da falésia: a história entre incertezas e inquietude. Tradução de Patrícia Chittoni Ramos. Porto Alegre: Editora UFRGS, 2002. p. 61-80.

CHERVEL, A. História das disciplinas escolares: reflexões sobre um campo de pesquisa. Revista Teoria \& Educação, v. 2, p. 177-229, 1990.

DEL PRIORE, M.; VENÂNCIO, R. Uma história da vida rural no Brasil. Rio de Janeiro: Ediouro, 2006.

DIÁRIO DO GRAM-PARÁ. 3 de maio de 1860, p. 1.

FARIA FILHO, L. M. de. Escolarização, cultura e práticas escolares no Brasil: elementos teóricos metodológicos de um programa de pesquisa. In: LOPES, A. C.; MACEDO, E. (Org.). Disciplina e integração curricular: história e políticas. Rio de Janeiro: DP\&A, 2002. p. 13-35. 
GATTI JUNIOR, D.; ARAÚJO, J. C. S. Novos temas em história da educação brasileira. Campinas: Autores Associados, 2002.

HILSDORF, M. L. S. História da educação brasileira: leituras. São Paulo: Pioneira Thomson Learning, 2003.

INSTITUTO HISTÓRICO GEOGRÁFICO BRASILEIRO. IHGB. Relatório do diretor da instrução pública do Pará. De Felix Barreto de Vasconcellos, diretor, por solicitação do Presidente da Província, Major Manoel de Frias e Vasconcellos 20/12/1858. Coleção Manuel Barata. Documento manuscrito, não publicado no relatório provincial, 1858.

JACOMELI, M. R.; MOLINA, R. S. História da educação agrícola no século XIX: formação gestora e operária no Brasil. In: IXJORNADA DO HISTEDBR, 9., 2010, Belém. Anais... Belém: HISTEDBR, 2010.

JULIA, D. A cultura escolar como objeto histórico. Revista Brasileira de História da Educação, v. 1, p. 9-43, 2001.

MUNIZ, P. Estado do Grão-Pará: imigração e colonização. História e Estatística 16161916. Belém: Imprensa Official do Estado do Pará, 1916.

NERY, V. S. C. Instrução pública primária na província do Pará na segunda metade do século XIX. 2013. 152 f. Dissertação (Mestrado em Educação) - Universidade do Estado do Pará, Belém, 2013.

NÓVOA, A. A Imprensa de Educação e Ensino: concepção e organização do repertório Português. In: CATANI, D. B.; BASTOS, M. H. C. (Org.). Educação em revista: a imprensa periódica e a história da educação. São Paulo: Escritura, 1997. p. 11-31.

NUNES, F. A. A semente da colonização: um estudo sobre a colônia agrícola de Benevides (Pará 1870-1889). 2008. 228 f. Dissertação (Mestrado em História Social da Amazônia) - Universidade Federal do Pará, Belém, 2008.

NUNES, F. A. Quando a educação "civiliza": ciência agronômica e ensino no projeto de criação da Escola Rural Pedro II (Pará, Anos de 1860). Revista Areté, v. 7, p. 170-181, 2014.

NUNES, F. A. Sob o signo do moderno cultivo: estado imperial e agricultura na Amazônia. 2011. 422 f. Tese (Doutorado em História Social/Contemporânea) Universidade Federal Fluminense, Rio de Janeiro, 2011.

O LIBERAL DO PARÁ. Belém: 6 de abril de 1879, p. 01. 
PARÁ. Discurso. Recitado pelo Presidente da Província, João Antonio de Miranda, na abertura da Assembléia Legislativa Provincial. Em 15 de Agosto de 1840, Pará, Typ. Santos, 1840.

PARÁ. Exposição. Apresentada pelo Exmo. Sr. Conselheiro Sebastião do Rego Barros, Presidente da Província do Gram-Pará, ao Exmo. Tenente Coronel, de Engenheiros Henrique Beaurepaire Rohan, no dia 29 de maio de 1856, por ocasião de passar-lhe a administração da mesma província. Pará, Typ. Santos \& Filho, 1856.

PARÁ. Falla. Dirigida a Assembleia Legislativa da Província do Pará na segunda sessão da, décima primeira legislatura pelo Exmo. Sr. Tenente Coronel Manoel, de Frias e Vasconcelos, presidente da mesma província, em $1^{\circ}$ de outubro de 1859. Pará, Typ. Commercial de Antônio José Rabelo Guimarães, 1859.

PARÁ. Falla. Dirigida pelo Exmo. Dr. Fausto Augusto D’Aguiar, Presidente da Província do Pará, na abertura da primeira sessão ordinária da sétima legislatura da Assembleia Legislativa Provincial no dia 10 de outubro de 1850. Pará, Typ. Santos \& Filho, 1850.

PARÁ. Falla. Dirigida pelo Exmo. Sr. Conselheiro Jerônimo Francisco Coelho, Presidente da Província do Pará, na abertura da sessão ordinária de sexta legislatura da Assembleia Legislativa Provincial no dia 10 de outubro de 1848. Pará, Typ. Santos \& Filho, 1848.

PARÁ. Falla. Dirigida pelo Exmo. Sr. Conselheiro Jerônimo Francisco Coelho, Presidente da Província do Pará, na abertura da segunda sessão ordinária da sexta legislatura da Assembleia Legislativa Provincial no dia 10 de outubro de 1849. Pará, Typ. Santos \& Filho, 1849.

PARÁ. Falla. Que o Exmo. Sr. Conselheiro Sebastião do Rego Barros, presidente desta província, dirigiu a Assembleia Legislativa Provincial na abertura da mesma no dia 15 de agosto de 1854. Pará, Typ. Santos \& Filho, 1854.

PARÁ. Falla. Que o Exmo. Sr. Dr. Joaquim da Cunha, presidente desta província, dirigiu a Assembléia Legislativa Provincial na abertura da mesma, no dia 15 de agosto de 1853. Pará, Typ. Santos \& Filho, 1853.

PARÁ. Falla. Que o Exmo. Sr. Dr. José Joaquim da Cunha, presidente da província, dirigiu a Assembleia Legislativa Provincial, na abertura da mesma, no dia 10 de setembro de 1852.Pará, Typ. Santos \& Filho, 1852.

PARÁ. Lei n. 226 de 15 de dezembro de 1853. Lex-Coleção das Leis da Província do Grão Pará. Belém: Typ. Santos \& Filho, 1853. 
PARÁ. Palestra. Falla com que o Excl. Sr. Dr. João Capistrano Bandeira de Mello Filho, abriu a segunda sessão da vigésima legislatura da Assembleia Legislativa da Província do Pará, em 15 de fevereiro de 1877. Belém; Typ. do Livro do Commercio, 1877.

PARÁ. Relatório. Apresentado a Assembleia Legislativa da Província do Pará na primeira sessão da décima segunda legislatura pelo Exmo. Sr. Presidente da Província. Dr. Francisco, de Araújo Brusque em 10 de setembro de 1862. Pará Typ. Frederico Carlos Rhossard, 1862.

PARÁ. Relatório. Apresentado a Assembleia Legislativa da Província do Pará na segunda sessão da décima terceira legislatura pelo Exmo. Sr. Presidente da Província. Dr. Francisco, de Araújo Brusque em 10 de novembro de 1863. Pará Typ. Frederico Carlos Rhossard, 1863.

PARÁ. Relatório. Apresentado a Assembleia Legislativa Provincial do Pará, no dia 10 de agosto de 1857, por ocasião da abertura da segunda sessão da décima legislatura da mesma assembleia, pelo presidente Henrique Beaurepaire Rohan. Pará, Typ. Santos \& Filho, 1857.

PARÁ. Relatório. Apresentado a Assembleia Legislativa Provincial do Pará no dia 15 de agosto de 1856, por ocasião da abertura da primeira sessão da $10^{\circ}$ legislatura da mesma, pelo presidente, Henrique Beaurepaire Rohan. Pará, Typ. Santos \& Filho, 1856.

PARÁ. Relatório. Apresentado a Assembleia Legislativa Provincial na primeira legislatura pelo quarto vice-presidente, Dr. Abel Graça. Pará, Typ. do Diário do GramPará, 1870.

PARÁ. Relatório. Apresentado a Assembleia Legislativa Provincial na primeira sessão da décima oitava legislatura em 15 de fevereiro de 1872, pelo presidente da província Dr. Abel Graça. Pará, Typ. Diário do Gram-Pará, 1872.

PARÁ. Relatório. Apresentado a Assembleia Legislativa Provincial pelo Excl. Sr. Vice Almirante e conselheiro de Guerra Joaquim Raymundo da Lamare, Presidente da Província, em 15 de agosto de 1867. Pará, Typ. Frederico Rhossard, 1867.

PARÁ. Relatório. Apresentado ao Excl. Sr. Dr. Francisco Maria Corrêa de Sá e Benevides pelo Excl. Sr. Dr. Pedro Vicente de Azevedo, por ocasião de passar-lhe a administração da província do Pará, no dia 17 de janeiro de 1875. Pará, Typ. de F.C. Rhossard, 1875.

PARÁ. Relatório. Apresentado ao Exmo. Sr. Dr. José Joaquim da Cunha, presidente da Província do Gram Pará, pelo comendador Fausto d' Aguiar por ocasião de entregar-lhe a administração da província no dia 20 de agosto de 1852. Pará, Typ. Santos \& Filho, 1852. 
PARÁ. Relatório. Apresentado pelo excellentissimo senhor doutor José Coelho da Gama e Abreu, presidente da provincia, á Assembléa Legislativa Provincial do Pará, na sua 1.a sessão da 22.a legislatura, em 15 de fevereiro de 1880. Pará, 1880.

PARÁ. Relatório. Com que o Excl. Sr. Dr. Francisco Maria Corrêa de Sá e Benevides, presidente da província, abriu a segunda sessão da décima nona legislatura da Assembléia Legislativa Provincial no dia 15 de fevereiro de 1875. Pará, Typ. do Diário do Gram-Pará, 1875 .

PARÁ. Relatório. Com que o Excl. Sr. Presidente da Província Dr. Pedro Leão Vellozo passou a administração da mesma ao Excl. Sr. $1^{\circ}$ Vice-Presidente, Barão do Arary, no dia 29 de abril de 1867. Pará, Typ. De Frederico Rhossard, 1867.

PARÁ. Relatório. Dirigido a Assembleia Legislativa do Pará na segunda sessão da décima segunda Legislatura pelo Exmo. Sr. Dr. Francisco Carlos de Araújo Brusque, presidente da mesma província, em 17 de agosto de 1861. Belém: Typ. Diário do Gram-Pará, 1861.

PARÁ. Relatório. Dirigido a Assembleia Legislativa do Pará na segunda sessão da vigésima segunda legislatura em 15 de fevereiro de 1881 pelo Exmo. Sr. Dr. José Coelho da Gama e Abreu. Belém: Typ. Diário de Noticias do Costa \& Campbell, 1881.

PARÁ. Relatório. Feito pelo Exmo. Sr. Conselheiro Jerônimo Francisco Coelho, presidente desta província e entregue ao $1^{\circ}$ vice-presidente em exercício, o Exmo. Sr. Dr. Ângelo, Custodio Correa, no dia 10 de agosto de 1850. Pará, Typ. Santos \& Filho, 1850.

PARÁ. Relatório. Negócios da Província do Pará. Pará, Typ. Frederico Rhossard, 1864. Athead of title: Dr. Couto de Magalhães, Presidente do Pará 1864. Cover title: Relatório dos negócios da provincial do Pará seguido de uma viagem ao Tocantins até a cachoeira das Guaribas e as Bahias do Rio Anapú, pelo secretário da província, Domingos Soares Ferreira Pena, da exploração e exame do mesmo rio até acima das últimas cachoeiras depois de sua junção como o Araguaya, pelo capitão-tenente da armada.

PARÁ. Relatório. Presidência do Pará, apresentado a respectiva Assembleia Legislativa provincial pelo excelentíssimo senhor vice-presidente Barão de Arary, em $1^{\circ}$ de outubro de 1866. Pará, Typ. Jornal do Amazonas, 1866.

PARÁ. Relatório. Relatório apresentado pelo Exmo. Sr. Dr. Francisco Maria Corrêa de Sá e Benevides, presidente da provincia do Pará, á Assembléia Legislativa Provincial na sua sessão solemne de installação da 20.a legislatura, no dia 15 de fevereiro de 1876. Pará, 1876.

PARÁ. Relatório. Secretário da Província. Pará Typ. Frederico Rhossard, 1864. At head of title: O Tocantins e o Anapú. Bound with item nº 527. 
PENTEADO, A. R. Problemas de colonização e de uso da terra na região bragantina do Estado do Pará. Belém: Universidade Federal do Pará, 1967.

PESAVENTO, S. J. História \& história cultural. 2. ed. Belo Horizonte: Autêntica, 2008.

RIZZINI, I. O cidadão polido e o selvagem bruto: a educação dos meninos desvalidos na Amazônia Imperial. Rio de Janeiro: UFRJ/IFCS/PPGHIS, 2004.

SANTOS, R. A. de. O. História econômica da Amazônia (1900-1920). São Paulo, 1984.

SOUZA, R. F. Cultura Material Escolar. Cadernos Cedes, Araraquara, ano 10, n. 52, nov.2000.

Notas

\footnotetext{
${ }^{1}$ Doutorando do Programa de Pós-Graduação em Educação da Universidade Federal do Pará (PPGEDUFPA), Mestre em Educação (UEPA/PUC-RIO) e professor da Universidade do Estado do Amapá (UEAP); Líder do Grupo de Estudos Pesquisas e Práticas em Educação na Amazônia Amapaense (GEPEA), E-mail: vitor.nery@ueap.edu.br

${ }^{2}$ Pós-Doutora em História da Educação pela Pontifícia Universidade Católica do Rio Grande do Sul, Doutora em História, Filosofia e Educação pela Universidade Estadual de Campinas, Professora Adjunta do Curso de Pedagogia e do Programa de Pós Graduação da Universidade do Estado do Pará; Líder do Grupo de Pesquisa História da Educação na Amazônia-GHEDA, E-mail: socorroavelino@hotmail.com

${ }^{3} \mathrm{Em} 15$ de novembro de 1853, a Lei Provincial n. 226 criou no tesouro público provincial um caixa especial, destinado exclusivamente a adiantar fundos às empresas que fossem formadas com o objetivo de introduzir colonos na província (PARÁ, 1853, p. 33).
}

Submetido em: 30/04/2016

Aprovado em: 25/08/2017 